\title{
Living Stories of Resilience, Resistance, and Resourcefulness
}

\author{
Nathan Carlin ${ }^{1} \cdot$ Donald Capps $^{2} \cdot$ Robert C. Dykstra $^{2}$
}

Published online: 5 July 2015

(C) Springer Science+Business Media New York 2015

The articles in this special issue of the journal were presented as working papers at two conferences of the Group for New Directions in Pastoral Theology at Princeton Theological Seminary on May 7-9 and October 1-3, 2014. Papers from previous conferences have been published as articles in Pastoral Psychology in the December 2010, June 2011, August 2012, October 2013, and December 2014 issues. We are deeply indebted to Lewis Rambo, editor of Pastoral Psychology, for enabling us to publish the articles as a group.

As in previous years, these two conferences had a common theme: "Living Stories of Resilience, Resistance, and Resourcefulness." This theme, which emerged from the closing discussions at the previous year's conferences in which participants were invited to propose the next year's theme, was chosen because pastoral theology, as a discipline, has focused over the years on the personal and collective experiences of individuals, families, friendship and support groups, local communities, congregations, and other religious groups; in addition, it has given particular attention to the racial, ethnic, gender, sexual orientation, economic, and health-related issues and concerns that these entities experience on an ongoing basis. As a group dedicated to the recognition and development of "new directions" in pastoral theology, we hoped to develop ideas and strategies for addressing these issues and concerns in new and helpful ways.

The theme's emphasis on "living stories" reflects the insight that came into prominence several decades ago that pastoral theology tends to be story-oriented. Whether the focus of attention is an individual, family, friendship or support group, local community, congregation, or other religious group or organization, pastoral theological studies have typically employed stories to illustrate and explore the concerns and issues being addressed. This story-orientation has its basis in the traditional emphasis of the discipline on the case study, which has been, and continues to be, a prominent feature of chaplaincy and pastoral counseling. However, the story-orientation allows for addressing the racial, ethnic, gender,

Nathan Carlin

Nathan.Carlin@uth.tmc.edu

1 McGovern Center for Humanities and Ethics, The University of Texas Medical School, 6431 Fannin Street, JJL 410, Houston, TX 77030, USA

2 Princeton Theological Seminary, P. O. Box 821, Princeton, NJ 08542-0803, USA 
sexual orientation, economic, and health-related issues that these various entities experience in a more fully developed way.

The phrase "living stories" is borrowed from the title of a book by one of the organizers of our conferences (Capps 1998). This title reflects the focus of pastoral theology on the stories of persons, groups, and communities that are seeking to live their lives as fully as possible. This means, of course, that pastoral theology needs to pay special attention to the situations and circumstances that inhibit or prohibit individuals, groups, and communities from living the lives that they were created to live.

To open up ways in which pastoral theology may do this more effectively, we decided to focus on the "three Rs" of resilience, resistance, and resourcefulness. These words had come up in our conversations around the table, and individual members of the group had previously written papers that employed these concepts. The novelty of the theme is that it brings these concepts together and, by doing so, invites exploration of their connections and creatively plays them off one another. To assist the conference participants in this endeavor, definitions of the three terms proved rather useful. Resilience is the ability to bounce or spring back into shape or position after being pressed or stretched. Implied in this definition is the ability to recover strength, spirits, good humor, etc., and to do so quickly and with a sense of buoyancy. Resistance refers to the power or capacity to resist, specifically the ability of an organism to ward off disease. Although this definition focuses on the physical organism (e.g., the human body), it also suggests that resistance is the capacity to ward off diseases that are social and societal and also that resistance involves the effort or work of collective bodies. Resourcefulness means the ability to deal creatively with problems and difficulties, and it implies making use of available resources that can be drawn upon for aid or to take care of a need. An individual, group, or community may already possess these resources but not realize that they have them or know how best to employ them. ${ }^{1}$

As noted in previous special issues of Pastoral Psychology devoted to the Group for New Directions in Pastoral Theology, the number of participants is necessarily limited given the structure of the conference meetings (one hour of discussion is dedicated to each paper). Despite the limited size of the group, certain principles have guided invitations to participants since its inception. The principles that have guided these invitations are that: (1) scholars at every stage should be included (e.g., doctoral students and assistant, associate, full, and emeriti professors); (2) the group should be diverse in terms of race, ethnicity, gender, sexual orientation, nationality, and age; (3) the conference should be small, consisting ideally of 12-14 participants, so as to provide a venue for thoughtful discussion of each paper over a three-day period; and (4) there should be an attempt to publish the papers so as to reach a wider readership of pastoral theologians as well as scholars and practitioners in related disciplines and professions.

In the years since the Group has been meeting, 35 pastoral theologians have presented the conference, and a total of 45 have been invited. We believe that these meetings have provided a rich opportunity for engaging in thoughtful dialogue over the years. Friendships have been

\footnotetext{
${ }^{1}$ These three definitions are on two adjoining pages of Webster's New World College Dictionary (Agnes et al. 2000, pp. 1220-1221).
} 
made and strengthened at these meetings, and as the Group has evolved over time, new voices have added to the conversations that occur among these travelers who continually seek out new locations to visit and explore.

\section{References}

Agnes, M., et al. (Eds.). (2000). Webster's new world college dictionary. Foster City: IDG Books Worldwide. Capps, D. (1998). Living stories: Pastoral counseling in congregational context. Minneapolis: Fortress Press. 